\title{
The stroke offspring study: is parental stroke history of value in targeted risk factor screening?
}

\author{
Nigel D. Hart' ${ }^{1}$, Margaret E. Cupples ${ }^{2}$, M. Ivan Wiggam ${ }^{3}$, Christopher C. Patterson $^{1}$ and \\ John W.G. Yarnell ${ }^{1}$ \\ ${ }^{1}$ Centre for Public Health, School of Medicine, Dentistry and Biomedical Sciences, Queen's University Belfast, \\ Belfast, UK \\ ${ }^{2}$ Centre for Public Health \& UKCRC Centre of Excellence for Public Health Research (Northern Ireland), \\ School of Medicine, Dentistry and Biomedical Sciences, Queen's University Belfast, Belfast, UK \\ ${ }^{3}$ Belfast City Hospital, Belfast, UK
}

\begin{abstract}
Aim: This study aimed to compare the prevalence of stroke risk factors among people with a parental history of stroke to those in a control group of individuals, of similar age, gender and social class, with no parental stroke history. Background: Parental stroke increases an individual's risk of stroke, but little is known of the potential value of using this information in targeted screening for primary prevention in general practice. Method: We sent questionnaires to 300 randomly selected individuals aged $40-65$ years, in each of 11 different general practices in Northern Ireland. Among 1061 responses received within six weeks, 332 reported a parental history of stroke (31.3\%). We matched respondents with (cases) and without (controls) a parental history of stroke on characteristics of age, gender and socioeconomic status. Matched pairs were invited to attend a consultation at which their diet and exercise habits were assessed using validated questionnaires and height, weight, blood pressure and serum lipids and glucose were measured. Findings: Matched data were available for 199 case-control pairs (398 individuals). Mean systolic and diastolic blood pressures were significantly higher in cases than in paired controls (systolic 146.3 versus $140.6 \mathrm{mmHg}(P<0.01)$; diastolic 87.7 versus $85.0 \mathrm{mmHg}(P=0.014)$ ). Cases consumed more alcohol than their paired controls (13.8 versus $10.1 \mathrm{U} /$ week $(P<0.01))$, but their measures of body mass index, lipids, diabetes, diet and exercise did not differ significantly. The results of this study suggest that screening offspring of patients with stroke in respect of blood pressure has potential value in identifying people likely to benefit from primary prevention, but do not support the adoption of a targeted screening strategy for other commonly cited stroke risk factors.
\end{abstract}

Key words: blood pressure; cardiovascular risk factors; family history; general practice; screening; stroke

Received 21 December 2009; accepted 4 May 2010; first published online 7 July 2010

\section{Introduction}

Stroke is the leading cause of death and disability worldwide (Lopez et al., 2006) despite the knowledge that its risk can be reduced by the

Correspondence to: Dr Nigel Hart, Senior Lecturer, Department of General Practice, Dunluce Health Centre, Queen's University Belfast, Belfast BT9 7HR, UK. Email: n.hart@qub.ac.uk

(C) Cambridge University Press 2010 appropriate management of modifiable cardiovascular risk factors (Goldstein et al., 2006).

Studies show that parental stroke is an independent risk factor for stroke (Jousilahti et al., 1997; Polychronopoulos et al., 2002) and, in those who have suffered a primary cerebrovascular event, there is evidence of an association between family history of stroke and modifiable risk (Flossmann and Rothwell, 2005; Lindgren et al., 2005). Lindgren 
found that first-degree relatives of people who had suffered a stroke reported a higher prevalence of hypertension than did relatives of controls who had not suffered a stroke (Lindgren et al., 2005), but this finding was not linked to any validated measurements.

There is evidence to suggest that individuals with a parental history of cardiovascular disease do not pursue self-initiated, sustained change in modifiable risk factors (Kip et al., 2002). Thus, opportunities may exist for improving primary prevention of stroke through targeted screening of individuals with a relevant parental history, for risk identification and reduction. However, there is a lack of evidence of the relative prevalence of modifiable risk factors between those with and without a parental history of stroke or of the potential value of adopting such a strategy in general practice.

This study therefore aimed to compare, in the general population, the prevalence of stroke risk factors, among people with a parental history of stroke, to those in a control group of individuals, of similar age, gender and social class, with no parental stroke history.

\section{Methods}

\section{Design}

We carried out a case-control study of individuals from 11 selected general practices in Northern Ireland (NI) between August 2004 and July 2005. These practices were chosen to represent the general population of NI and included a range of geographical location, practice list size, deprivation scores and population density. Three hundred individuals from the total population in each practice falling between the ages of 40 and 65 years (the 'invitees') were selected using random number assignment (Urbaniak and Plous, 2005). A questionnaire was sent relating to a history of parental stroke, sociodemographic information and consent for contact by the researcher. A pre-paid preaddressed envelope was included for return. Replies received within six weeks of posting (the 'responders') were considered for recruitment to the study; those received later were excluded.

\section{Recruitment}

Within each practice those with a parental history of stroke were matched to individuals with no parental stroke history. Matching was performed on gender, age ( \pm 5 years) and socioeconomic status $( \pm 10)$ using a commonly used regional index of multiple deprivation (IMD; Noble et al., 2001) (scored from 0 to 100) derived from the postal code of the place of residence. Potential participants were telephoned on at least three occasions, at a variety of times including evening, before attempted contact was abandoned. Those contacted were invited to attend their own general practice surgery (the 'attendees') to meet with the researcher for an interview and medical examination.

\section{Data collection}

At interview, following written consent, biographical and sociodemographic data were collected by the researcher. Data were gathered about the symptoms observed at the time of the stroke of their parent in order to provide some validation of the diagnosis. Participants were asked about their own relevant past medical history, current medications and smoking and alcohol consumption. Height was measured (to nearest $0.1 \mathrm{~cm}$ ) using a stadiometer (Seca 214 Portable Stadiometer, Hamburg, Germany) and weight (to nearest $1 \mathrm{~kg}$ ) using mechanical clinical scales (Seca 761 Medical Scales, Hamburg, Germany). Waist circumference (widest point of abdomen below bottom of rib cage and above iliac crest) and hip circumference (maximum width over greater trochanters of the pelvic girdle) were measured using a tape measure to the nearest $1 \mathrm{~cm}$. Body mass index $(\mathrm{BMI})\left(\mathrm{kg} / \mathrm{m}^{2}\right)$ and waist-hip ratio (WHR) were each derived. Resting non-invasive brachial arterial blood pressure was measured (Williams et al., 2004) twice, with a 3-min gap between the first and second measurements, using an approved validated automated oscillometric device (Omron HEM-705CP, Omron, Schaumburg, IL, USA) (O'Brien et al., 1996; The British Hypertension Society, 2006); the second measurement was used for analysis. Participants with a blood pressure above $140 / 90 \mathrm{mmHg}$ (Williams et al., 2004) were asked to return to their own general practitioner for further checks. Results of blood tests were returned to each practice with abnormal results highlighted for attention.

Participants completed one validated questionnaire for dietary habit (Dietary Instrument for Nutrition Education questionnaire (Roe et al., 1994; 
Little and Margetts, 1996)) and another for exercise habit (Baecke Physical Activity Questionnaire; Baecke et al., 1982).

\section{Data analysis}

A number of dichotomous variables were derived for analysis. 'Raised blood pressure' was defined as a history of hypertension, currently taking anti-hypertensive medication, systolic blood pressure (SBP) above $140 \mathrm{mmHg}$ or diastolic blood pressure (DBP) above $90 \mathrm{mmHg}$ (Williams et al., 2004). 'Raised cholesterol' included participants with TChol/high-density lipoprotein (HDL) ratio above 5.0. An individual was deemed to have diabetes if they reported a history of diabetes, were currently taking diabetic medication or their fasting blood glucose was above $6.9 \mathrm{mmol} / \mathrm{L}$ (The Expert Committee on the Diagnosis and Classification of Diabetes Mellitus, 1997). Alcohol intake was categorised using recommeded limits for weekly consumption ( $21 \mathrm{U}$ for men; $14 \mathrm{U}$ for women; Mulvihill et al., 2005). Using a conversion of $8 \mathrm{~g}$ alcohol per unit (Miller et al., 1991), units consumed per week were converted into grams of alcohol per day and recoded into another categorical variable (greater or less than $60 \mathrm{~g}$ of alcohol per day), based on a meta-analysis detailing alcohol levels that were clinically significant (Reynolds et al., 2003). 'Metabolic syndrome' was defined by the presence of central obesity (abdominal circumference $\geqslant 94 \mathrm{~cm}$ for men and $\geqslant 80 \mathrm{~cm}$ for women) plus two of the following: raised triglycerides $(>1.7 \mathrm{mmol} / \mathrm{L})$, reduced HDL cholesterol $(<1.03 \mathrm{mmol} / \mathrm{L}$ for males and $1.29 \mathrm{mmol} / \mathrm{L}$ for females), raised blood pressure (SBP $\geqslant 130 \mathrm{mmHg}$ or $\mathrm{DBP} \geqslant 85 \mathrm{mmHg}$ )) and raised fasting blood glucose ( $\geqslant 5.6 \mathrm{mmol} / \mathrm{L}$; Alberti et al., 2005).

SPSS (Statistics Computer Programme 15.0.1 Release November 2006) was used for data entry and analysis. Descriptive statistics were used to summarise data. Continuous variables were compared for casecontrol pairs using a $t$-test for paired samples. Categorical variables were analysed using McNemar's test for non-parametric data. For variables with missing data, case-control data pairs were removed from the analysis. Multiple regression analysis was used to adjust paired comparisons of blood pressure between cases and controls for confounding variables.

Sample size was based on an assumption of risk factor prevalence (eg, current cigarette smoking or hypertension) of $30 \%$ in the control group. A $50 \%$ difference between the groups (ie, $30 \%$ versus $45 \%$ ) in risk factor prevalence would be detected at the 5\% significance level and power greater than $80 \%$ with independent samples of 200 cases and 200 controls.

\section{Ethics approval}

Ethics approval to conduct the study was sought and granted by the Queen's University Belfast Research Ethics Committee.

\section{Results}

The total population of the 11 practices from which the study sample was drawn was 104207 , which represents $6.2 \%$ of the NI population. Of the 3300 questionnaires sent, 1061 (32\%) were returned within six weeks of posting. Completed data were obtained for 199 case-control pairs (398 individuals; Figure 1). Comparing the study attendees to invitees, attendees were slightly older (mean age 53 years (SD 6.7) versus 51.2 years (SD 7.0; $P<0.001)$ ), had lower levels of deprivation (IMD 16.7 (SD 16.4) versus 23.2 (SD 20.8; $P<0.001)$ ) and had a greater representation of females (54.5\% versus $51.4 \%$; Table 1$)$. Comparison of cases and controls in respect of mean age (53.1 (SD 6.7) years versus 53.0 (SD 6.7) years) and mean deprivation status (IMD 16.8 (SD 16.7) versus 16.6 (SD 16.2)) confirmed successful matching on those characteristics.

Mean diastolic BP (DBP) was $2.7 \mathrm{mmHg}$ higher and mean systolic BP (SBP) $5.7 \mathrm{mmHg}$ higher in cases than in controls (Table 2). More cases than controls had 'raised blood pressure', but the difference was not statistically significant $(P=0.07)$. Cases were more likely than controls to have a prior diagnosis of hypertension and to be on anti-hypertensive medication.

A greater proportion of cases than controls declared a history of hypercholesterolaemia, diabetes mellitus, previous stroke, previous myocardial infarction, atrial fibrillation and ischaemic heart disease, but these differences were not statistically significant (Table 3 ).

Similar proportions of cases and controls were both current smokers and considered to have a 'smoking-associated risk' (current smoker 
or exsmoker of $<10$ years). Cases consumed a mean of $3.7 \mathrm{U}$ of alcohol more per week than their paired controls. In addition, significantly more cases than controls consumed above the recommended limits. No significant differences were found between cases and controls for measures of lipids, glucose, diabetes, BMI, WHR, dietary habit or physical activity. However, it was noted that differences in fasting blood glucose and triglycerides between groups approached statistical significance.

A regression analysis was carried out to adjust the blood pressure comparisons for BMI, smoking,

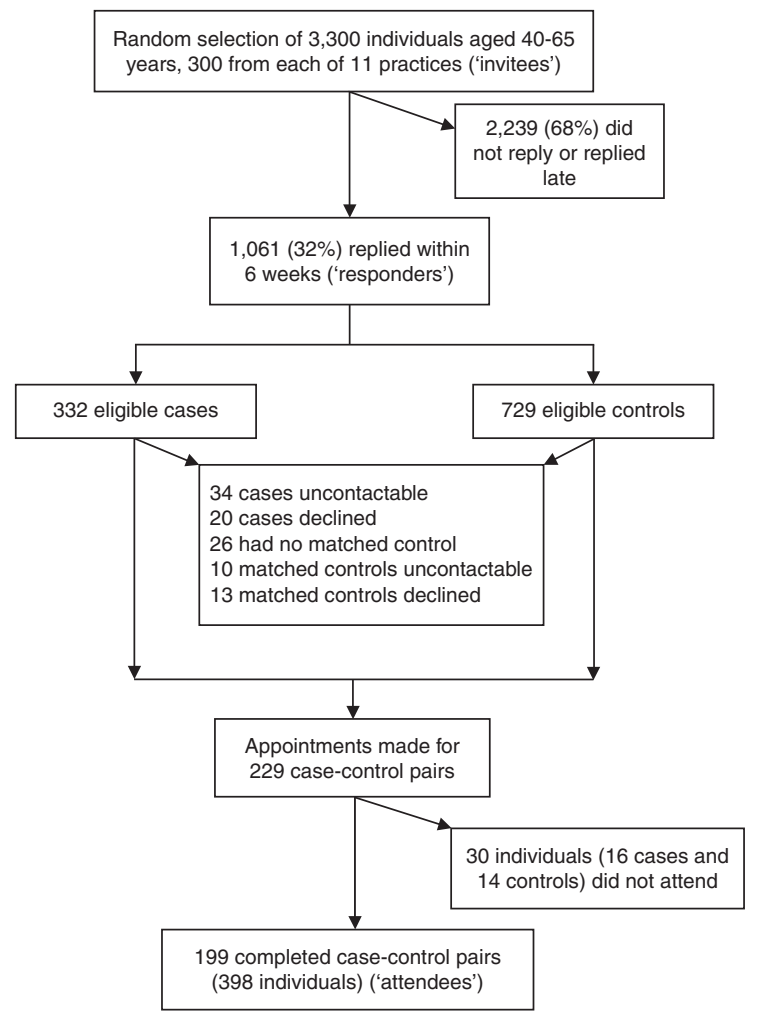

Figure 1 Flow diagram of recruitment process alcohol consumption, fasting blood glucose and diabetic mellitus history (Table 4). After adjustment, the difference between cases and controls remained statistically significant for SBP, but for DBP the difference between cases and controls failed to reach significance.

\section{Discussion}

This study shows that screening individuals with a parental history of stroke for stroke risk factors returns significantly higher mean systolic and DBP and higher alcohol consumption compared with those with no parental history of stroke. Furthermore, the relative prevalence of hypertension and of alcohol consumption above recommended limits are higher among those with a parental history of stroke.

After regression analysis, with adjustment for other risk factors, a relationship between higher mean SBP and positive parental history of stroke remains. The mean difference between age- and gender-matched pairs in systolic BP is $5.7 \mathrm{mmHg}$, with a mean BP of $146 / 88 \mathrm{mmHg}$ for those with a parental history of stroke. Stroke risk has been shown to have a direct and linear relationship with blood pressure down to at least $115 / 75 \mathrm{mmHg}$ (Lewington et al., 2002), and a meta-analysis has shown that a reduction of $10 \mathrm{mmHg}$ of systolic BP in those under 60 years was associated with a $40 \%$ to $50 \%$ reduction in stroke risk (Lawes et al., 2004).

The findings of our study add to the evidence from previous work of the relevance of selfreported hypertension in those with a family history of stroke (Flossmann and Rothwell, 2005; Lindgren et al., 2005). In keeping with the relative importance of blood pressure for all stroke risk it may be that blood pressure is the most important element in the manifestation of that heritability. Either way the findings lend weight to the argument for targeting the offspring of patients with a history

Table 1 Summary characteristics of 'invitees', 'responders' and 'attendees'

\begin{tabular}{lllr}
\hline & $\begin{array}{l}\text { Invitees } \\
(n=3300)\end{array}$ & $\begin{array}{l}\text { Responders } \\
(n=1061)\end{array}$ & $\begin{array}{l}\text { Attendees } \\
(n=398)\end{array}$ \\
\hline Age (mean years (SD)) & $51.2(7.0)$ & $51.5(6.9)$ & $53.0(6.7)$ \\
Index of multiple deprivation (mean units (SD)) & $23.2(20.8)$ & $20.1(19.6)$ & $\begin{array}{r}16.7(16.4) \\
180(45.2)\end{array}$ \\
Males $(n(\%))$ & $1602(48.6)$ & $490(46.2)$ & $180(45.2)$ \\
\hline
\end{tabular}

Primary Health Care Research \& Development 2011; 12: 21-28 
Table 2 Summary of characteristics of 199 case-control pairs (continuous data)

\begin{tabular}{|c|c|c|c|c|c|}
\hline & \multirow{2}{*}{$\begin{array}{l}\text { Number } \\
\text { of pairs }\end{array}$} & \multirow{2}{*}{$\frac{\text { Case }}{\text { Mean (SD) }}$} & \multirow{2}{*}{$\begin{array}{l}\text { Control } \\
\text { Mean (SD) }\end{array}$} & \multirow{2}{*}{$\begin{array}{l}\text { Paired difference } \\
(95 \% \mathrm{Cl})\end{array}$} & \multirow[t]{2}{*}{$P$-value } \\
\hline & & & & & \\
\hline Diastolic blood pressure $(\mathrm{mmHg})$ & 199 & 87.7 (11.4) & $85.0(11.5)$ & $2.7(0.6,4.8)$ & 0.014 \\
\hline Systolic blood pressure (mmHg) & 199 & $146.3(19.7)$ & $140.6(19.8)$ & $5.7(2.0,9.3)$ & 0.003 \\
\hline Total cholesterol (mmol/L) & 197 & $5.20(0.93)$ & $5.21(0.87)$ & $0.00(-0.18,0.18)$ & 0.987 \\
\hline HDL cholesterol (mmol/L) & 196 & $1.54(0.45)$ & $1.54(0.44)$ & $0.00(-0.08,0.08)$ & 0.966 \\
\hline Total cholesterol/HDL ratio & 196 & $3.6(1.2)$ & $3.6(1.1)$ & $0.0(-0.2,0.3)$ & 0.679 \\
\hline Triglycerides (mmol/L) & 197 & $1.55(1.11)$ & $1.38(0.80)$ & $0.18(-0.01,0.37)$ & 0.07 \\
\hline Fasting glucose $(\mathrm{mmol} / \mathrm{L})$ & 197 & $5.3(1.5)$ & $5.1(1.1)$ & $0.2(0.0,0.5)$ & 0.096 \\
\hline Units of alcohol per week (units) & 199 & $13.8(18.2)$ & $10.1(12.4)$ & $3.7(1.1,6.4)$ & 0.006 \\
\hline BMI $\left(\mathrm{kg} / \mathrm{m}^{2}\right)$ & 199 & $27.9(5.2)$ & $27.3(4.9)$ & $0.6(-0.4,1.6)$ & 0.22 \\
\hline Waist-hip ratio & 199 & $0.89(0.08)$ & $0.88(0.08)$ & $0.01(-0.01,0.02)$ & 0.316 \\
\hline DINE dietary fibre index & 195 & $35.0(14.3)$ & $35.5(11.4)$ & $-0.6(-3.0,1.9)$ & 0.647 \\
\hline DINE total fat index & 194 & $30.3(12.1)$ & $32.1(11.0)$ & $-1.8(-4.0,0.4)$ & 0.113 \\
\hline DINE unsaturated fat index & 156 & $10.5(2.7)$ & $10.2(2.4)$ & $0.3(-0.3,0.9)$ & 0.262 \\
\hline Baecke leisure physical activity index (0-5) & 165 & $2.8(0.6)$ & $2.8(0.6)$ & $0.0(-0.1,0.1)$ & 0.919 \\
\hline Baecke sports physical activity index (0-5) & 157 & $2.3(0.7)$ & $2.4(0.8)$ & $-0.1(-0.2,0.1)$ & 0.419 \\
\hline Baecke work physical activity index (0-5) & 84 & $2.8(0.7)$ & $2.8(0.8)$ & $0.1(-0.1,0.3)$ & 0.518 \\
\hline
\end{tabular}

$\mathrm{BMI}=$ body mass index; DINE = Dietary Instrument for Nutrition Education.

Table 3 Summary of characteristics of 199 case-control pairs (categorical data)

\begin{tabular}{|c|c|c|c|c|c|}
\hline & \multirow{2}{*}{$\begin{array}{l}\text { Number } \\
\text { of pairs }\end{array}$} & \multirow{2}{*}{$\frac{\text { Case }}{n(\%)}$} & \multirow{2}{*}{$\begin{array}{l}\text { Control } \\
n(\%)\end{array}$} & \multirow{2}{*}{$\begin{array}{l}\text { Paired difference } \\
(95 \% \mathrm{Cl})\end{array}$} & \multirow[t]{2}{*}{$P$-value } \\
\hline & & & & & \\
\hline History of hypertension & 199 & $66(33)$ & $40(20)$ & $13(5,21)$ & 0.002 \\
\hline History of hypercholesterolaemia & 199 & $40(20)$ & $26(13)$ & $7(0,14)$ & 0.08 \\
\hline History of diabetes mellitus & 199 & $16(8)$ & $9(5)$ & $3(-1,8)$ & 0.23 \\
\hline History of stroke & 199 & $2(1)$ & $1(1)$ & $-^{\mathrm{a}}$ & 1.00 \\
\hline History of myocardial infarction & 199 & $4(2)$ & $4(2)$ & $-^{a}$ & 1.00 \\
\hline History of ischaemic heart disease & 199 & $17(9)$ & 10(5) & $4(-2,9)$ & 0.25 \\
\hline History of atrial fibrillation & 199 & $2(1)$ & $0(0)$ & ${ }^{a}{ }^{a}-b_{1}$ & 0.50 \\
\hline On medication for hypertension & 199 & 61 (31) & $40(20)$ & $11(2,19)$ & 0.01 \\
\hline $\begin{array}{l}\text { Raised blood pressure ('history of hypertension', } \\
\text { on anti-hypertensive medication or BP }>140 / 90 \text { ) }\end{array}$ & 199 & $133(67)$ & $115(58)$ & $9(-1,19)$ & 0.07 \\
\hline Current smoker & 199 & $46(23)$ & $40(20)$ & $3(-5,11)$ & 0.53 \\
\hline $\begin{array}{l}\text { Smoking associated risk (current smoker or } \\
\text { ex-smoker of }<10 \text { years) }\end{array}$ & 199 & 70 (35) & $66(33)$ & $2(-8,12)$ & 0.75 \\
\hline Total cholesterol/HDL ratio $>5.0$ & 196 & $21(11)$ & $20(10)$ & $1(-6,7)$ & 0.87 \\
\hline $\begin{array}{l}\text { Diabetes mellitus (history of diabetes or fasting } \\
\text { glucose }>6.9 \mathrm{mmol} / \mathrm{L} \text { ) }\end{array}$ & 197 & 22 (11) & $12(6)$ & $5(-1,11)$ & 0.12 \\
\hline $\begin{array}{l}\text { Alcohol above recommended limits (males:21 } \\
\text { units, females:14 units/week) }\end{array}$ & 199 & 57 (29) & $40(20)$ & $9(0,17)$ & 0.04 \\
\hline Alcohol consumption $>60 \mathrm{~g}$ daily & 199 & $7(4)$ & $1(1)$ & $3(0,6)$ & 0.07 \\
\hline Metabolic syndrome & 199 & $83(42)$ & $72(36)$ & $6(-4,15)$ & 0.27 \\
\hline
\end{tabular}

${ }^{a}$ Insufficient numbers to permit formal testing.

of stroke for blood pressure screening and monitoring in routine clinical practice.

The higher mean weekly alcohol consumption among cases compared with controls (14 versus $10 \mathrm{U} /$ week; $P<0.01)$ and greater proportion drinking above recommended limits $(29 \%$ versus $20 \%$; $P<0.05)$ were unexpected findings. These patterns of alcohol consumption may reflect other family-influenced lifestyle behaviours. However, their clinical significance is unclear given the lack of 
Table 4 Multiple regression analysis of mean differences between cases and controls in paired measures of blood pressure

\begin{tabular}{|c|c|c|c|c|}
\hline \multirow{2}{*}{ Adjustment } & \multicolumn{2}{|l|}{ Diastolic blood pressure } & \multicolumn{2}{|l|}{ Systolic blood pressure } \\
\hline & Mean difference $(95 \% \mathrm{Cl})$ & $P$-value & Mean difference $(95 \% \mathrm{Cl})$ & $P$-value \\
\hline Unadjusted & $2.7(0.6,4.8)$ & 0.01 & $5.7(2.0,9.3)$ & 0.003 \\
\hline Adjusted for BMI & $2.5(0.4,4.6)$ & 0.02 & $5.4(1.8,9.1)$ & 0.004 \\
\hline Adjusted for smoking & $2.7(0.5,4.8)$ & 0.02 & $5.7(2.0,9.4)$ & 0.002 \\
\hline Adjusted for alcohol (units/week) ${ }^{a}$ & $2.2(0.1,4.4)$ & 0.04 & $5.2(1.5,8.9)$ & 0.006 \\
\hline Adjusted for fasting glucose ${ }^{a}$ & $2.4(0.2,4.6)$ & 0.03 & $5.1(1.4,8.8)$ & 0.007 \\
\hline History of diabetes & $2.2(0.0,4.4)$ & 0.02 & $4.9(1.2,8.7)$ & 0.002 \\
\hline $\begin{array}{l}\text { Adjusted for BMI, smoking, alcohol } \\
\text { (units/week) }^{a} \text {, fasting glucose }{ }^{a} \text {, diabetes }\end{array}$ & $2.0(-0.1,4.2)$ & 0.07 & $4.9(1.2,8.7)$ & 0.009 \\
\hline
\end{tabular}

$\mathrm{BMI}=$ body mass index.

${ }^{\mathrm{a}} \log 10$ scale (after addition of 1 unit/week for alcohol).

consensus about the role that light-to-moderate alcohol consumption plays in stroke risk (Mukamal et al., 2005). A greater consensus exists around the role that alcohol consumed in large quantities plays in stroke risk, with a relative risk of 1.69 for total stroke for those consuming more than $60 \mathrm{~g}$ of alcohol per day compared with abstainers (Reynolds et al., 2003). Although not statistically significant, we observed a trend towards a higher proportion of people with a parental history of stroke consuming more than $60 \mathrm{~g}$ alcohol per day. The lack of statistical significance may have been due to an inadequate sample size given that the prevalence of this level of alcohol consumption was small $(4 \%, 1 \%)$ in both groups.

\section{Strengths}

This study was based in general practice, the setting in which application of its results is likely to be most relevant. The method used an introductory letter from the practice where the study was to take place. It was considered that this added credibility to the researcher's letter of invitation and contributed to the willingness of those contacted to participate, thus optimising the potential to obtain a representative sample.

A single researcher carried out all the assessments, thus providing standardisation of measurements and consistency of approach. Conversely, the potential for bias in measurement from an observer who was not blind to the group status of participants should also be acknowledged. These criticisms are at least partially addressed in that the study used, where possible, validated research tools such as the diet and exercise questionnaires and an automatic oscillometric sphygmomanometer, which were not observer-dependent. Biochemical analysis of blood samples was done blind to group status.

\section{Limitations}

Although we observed differences in measured BP, we also found that more of those with than without a parental history of stroke reported a history of hypertension $(33 \%$ versus $20 \% ; P<0.01)$ and were on anti-hypertensive treatment. Possible explanations for this are that those with a positive family history were aware of blood pressure as a stroke risk factor and pro-actively sought BP measurement or that physicians' awareness of parental history of stroke prompted BP screening. The observation prompts speculation as to whether treatment may have masked a greater true mean difference in blood pressure between cases and controls.

Within the study protocol there was no reliable way of confirming the parental history of stroke or stroke subtype as in many cases the parent was dead and their medical notes would not be accessible. However, only those who were able to recall signs and symptoms in keeping with the FAS test (Nor et al., 2004) (facial, arm or leg weakness or a disorder of speech) that suggested their parent had suffered a stroke were included in the study. Reassuringly, from work done in the Family Heart Study population, the $\kappa$-statistics for agreement between proband-reported family history and the self-reported personal history of stroke in members of the proband's family were 0.77 for a proband-reported father's history 
versus father's self-reported history of stroke and 0.76 for a proband-reported mother's history versus mother's self-reported history (Kornegay et al., 1997). Although the method adopted is unvalidated and lacks diagnostic rigour, it represents real-world clinical practice in which practitioners often do not have access to the notes of their patients' parents.

There may have been an attendance bias within the study as attendees were slighty older, more likely to be female and less socioeconomically deprived than invitees and responders. It may be that those attending were more health-conscious than non-responders and non-attendees. This may explain the failure to observe any difference in smoking prevalence between cases and controls: both may already have been following good advice in respect of stroke prevention and healthy lifestyles. However, the overall reported prevalence of smoking among the study population $(22 \%)$ is similar to recent estimates for smoking habits in Great Britain (General Household Survey, 2004), suggesting that the population studied is representative of the wider population in respect of smoking habits.

\section{Generalisability of the findings}

Within each general practice a random sample was drawn to avoid selection bias. However, a non-response bias, with consequent over-representation within our sample of those who were more health conscious, slightly older and of higher socioeconomic status, may remain a possibility as acknowledged above.

\section{Conclusion}

The results of this study suggest that targeting the offspring of patients with stroke as part of a screening strategy in respect of blood pressure may be worthwhile in identifying those for whom primary prevention would be a worthwhile step towards reducing the stroke burden. Given the assertion that individuals with a parental history of cardiovascular disease do not pursue selfinitiated, sustained change in modifiable risk factors (Kip et al., 2002) and the relative importance of blood pressure reduction for the primary prevention of stroke, such a strategy could be justified (Goldstein et al., 2006).
However, with the exception of alcohol consumption, the results do not support the adoption of a strategy to screen these individuals for all other commonly cited stroke risk factors. Further work would be required for a full understanding of the implications of the findings in respect of consumption of alcohol.

The introduction of a screening strategy to assess these risk factors in the offspring of all patients with a history of stroke would have implications for service provision. To avoid redundancy of effort, to ensure the appropriate use of limited resources and to provide a definitive answer of likely benefit, the adoption of a targeted screening strategy for blood pressure among the offspring of stroke patients would need to be measured against population strategies currently in use (NHS Confederation (Great Britain), 2003; British Cardiac Society et al., 2005; Goldstein et al., 2006; Jessani et al., 2006).

\section{Acknowledgements}

The study was funded by the Research and Development Office, Northern Ireland through a United Kingdom, National Health Service, Primary Care Researcher Development Award, awarded to Dr Nigel Hart. The authors declare no conflict of interest.

\section{References}

Alberti, K.G., Zimmet P., Shaw J. and IDF Epidemiology Task Force Consensus Group. 2005: The metabolic syndrome - a new worldwide definition. Lancet 366, 1059-62.

Baecke, J.A., Burema, J. and Frijters, J.E. 1982: A short questionnaire for the measurement of habitual physical activity in epidemiological studies. The American Journal of Clinical Nutrition 36, 936-42.

British Cardiac Society, British Hypertension Society, Diabetes UK, HEART UK, Primary Care Cardiovascular Society \& Stroke Association. 2005: JBS 2: Joint British Societies' guidelines on prevention of cardiovascular disease in clinical practice. Heart (British Cardiac Society) 91, (Suppl 5), v1-52.

Flossmann, E. and Rothwell, P.M. 2005: Family history of stroke in patients with transient ischemic attack in relation to hypertension and other intermediate phenotypes. Stroke; A Journal of Cerebral Circulation 36, 830-35.

General Household Survey. 2004: General Household Survey 2004. Smoking and drinking among adults. (Homepage of

Primary Health Care Research \& Development 2011; 12: 21-28 
Office of National Statistics). Retrieved 4 July 2006 from http://www.statistics.gov.uk/cci/nugget.asp?id=313

Goldstein, L.B., Adams, R., Alberts, M.J., Appel, L.J., Brass, L.M., Bushnell, C.D., Culebras, A., DeGraba, T.J., Gorelick, P.B., Guyton, J.R., Hart, R.G., Howard, G., KellyHayes, M., Nixon, J.V., Sacco, R.L. and American Heart Association \& American Stroke Association Stroke Council. 2006: Primary prevention of ischemic stroke: a guideline from the American Heart Association/American Stroke Association Stroke Council: cosponsored by the Atherosclerotic Peripheral Vascular Disease Interdisciplinary Working Group; Cardiovascular Nursing Council; Clinical Cardiology Council; Nutrition, Physical Activity, and Metabolism Council; and the Quality of Care and Outcomes Research Interdisciplinary Working Group. Circulation 113, e873-23.

Jessani, S., Watson, T., Cappuccio, F.P. and Lip, G.Y. 2006: Prevention of cardiovascular disease in clinical practice: The Joint British Societies' (JBS 2) guidelines. Journal of Human Hypertension 20, 641-45.

Jousilahti, P., Rastenyte, D., Tuomilehto, J., Sarti, C. and Vartiainen, E. 1997: Parental history of cardiovascular disease and risk of stroke. A prospective follow-up of 14371 middle-aged men and women in Finland. Stroke; A Journal of Cerebral Circulation 28, 1361-66.

Kip, K.E., McCreath, H.E., Roseman, J.M., Hulley, S.B. and Schreiner, P.J. 2002: Absence of risk factor change in young adults after family heart attack or stroke: the CARDIA study. American Journal of Preventive Medicine 22, 258-66.

Kornegay, C., Liao, D., Bensen, J., Province, M., Folsom, A. and Ellison, C.R. 1997: The accuracy of proband-reported family history of stroke: the FHS Study. American Journal of Epidemiology 145, 82.

Lawes, C.M., Bennett, D.A., Feigin, V.L. and Rodgers, A. 2004: Blood pressure and stroke: an overview of published reviews. Stroke; A Journal of Cerebral Circulation 35, 776-85.

Lewington, S., Clarke, R., Qizilbash, N., Peto, R., Collins, R. and Prospective Studies Collaboration. 2002: Age-specific relevance of usual blood pressure to vascular mortality: a meta-analysis of individual data for one million adults in 61 prospective studies. Lancet 360, 1903-13.

Lindgren, A., Lovkvist, H., Hallstrom, B., Hoglund, P., Jonsson, A.C., Kristoffersson, U., Luthman, H., Petersen, B. and Norrving, B. 2005: Prevalence of stroke and vascular risk factors among first-degree relatives of stroke patients and control subjects. A prospective consecutive study. Cerebrovascular Diseases (Basel, Switzerland) 20, 381-87.

Little, P. and Margetts, B. 1996: Dietary and exercise assessment in general practice. Family practice 13, 477-82.

Lopez, A.D., Mathers, C.D., Ezzati, M., Jamison, D.T. and Murray, C.J. 2006: Global and regional burden of disease and risk factors, 2001: systematic analysis of population health data. Lancet $367,1747-57$.

Miller, W.R., Heather, N. and Hall, W. 1991: Calculating standard drink units: international comparisons. British Journal of Addiction 86, 43-47.
Mukamal, K.J., Chung, H., Jenny, N.S., Kuller, L.H., Longstreth, W.T. Jr, Mittleman, M.A., Burke, G.L., Cushman, M., Beauchamp, N.J. Jr and Siscovick, D.S. 2005: Alcohol use and risk of ischemic stroke among older adults: the cardiovascular health study. Stroke; A Journal of Cerebral Circulation 36, 1830-34.

Mulvihill, C., Taylor, L. and Waller, S. 2005: Prevention and reduction of alcohol misuse, second edition. London: Health Development Agency. Retrieved 25 November 2009 from http:/www.nice.org.uk/nicemedia/documents/ alcoholEB2ndedition.pdf/

NHS Confederation (Great Britain). 2003: Investing in general practice: the new general medical services contract. London: NHS Confederation.

Noble, M., Smith, G., Wright, G., Dibben, C. and Lloyd, M. 2001: The Northern Ireland Multiple Deprivation Measure 2001. Belfast: Northern Ireland Statistics and Research Agency.

Nor, A.M., McAllister, C., Louw, S.J., Dyker, A.G., Davis, M., Jenkinson, D. and Ford, G.A. 2004: Agreement between ambulance paramedic- and physician-recorded neurological signs with face arm speech test (FAST) in acute stroke patients. Stroke; A Journal of Cerebral Circulation 35, 1355-59.

O'Brien, E., Mee, F., Atkins, N. and Thomas, M. 1996: Evaluation of three devices for self-measurement of blood pressure according to the revised British Hypertension Society protocol: the Omron HEM-705CP, Philips HP5332, and Nissei DS-175. Blood Pressure Monitoring 1, 55-61.

Polychronopoulos, P., Gioldasis, G., Ellul, J., Metallinos, I.C., Lekka, N.P., Paschalis, C. and Papapetropoulos, T. 2002: Family history of stroke in stroke types and subtypes. Journal of the Neurological Sciences 195, 117-22.

Reynolds, K., Lewis, B., Nolen, J.D., Kinney, G.L., Sathya, B. and He, J. 2003: Alcohol consumption and risk of stroke: a meta-analysis. JAMA: The Journal of the American Medical Association 289, 579-88.

Roe, L., Strong, C., Whiteside, C., Neil, A. and Mant, D. 1994: Dietary intervention in primary care: validity of the DINE method for diet assessment. Family Practice 11, 375-81.

The British Hypertension Society. 2006: Automatic digital blood pressure devices for clinical use. (Homepage of British Hypertension Society). Retrieved 2 June 2006 from http://www.bhsoc.org/bp_monitors/bp_archive.htm

The Expert Committee on the Diagnosis and Classification of Diabetes Mellitus. 1997: Report of the expert committee on the diagnosis and classification of diabetes mellitus. Diabetes Care 20, 1183-97.

Urbaniak, G.C. and Plous, S. 2005: Research randomizer Retrieved 23 March 2005 from http://www.randomizer.org/

Williams, B., Poulter, N.R., Brown, M.J., Davis, M., McInnes, G.T., Potter, J.F., Sever, P.S., McG Thom, S. and British Hypertension Society. 2004: Guidelines for management of hypertension: report of the fourth working party of the British Hypertension Society, 2004-BHS IV. Journal of Human Hypertension 18, 139-85. 